\title{
PENYULUHAN ROKOK \& NARKOBA DI SMP N 4 SIAK HULU
}

\author{
Cecen Suci Hakameri,S.Tr,Keb, M.Keb, Nia Septia Lisa, Nurul Latifa \\ STIKes Hang Tuah Pekanbaru \\ Email: Cecen.sh@gmail.com
}

\begin{abstract}
Cigarettes are addictive substances which when used can cause health hazards for individuals and society. Drugs are chemical substances that can change psychological conditions such as feelings, thoughts, moods and behavior when they enter the human body by eating, drinking, inhaling, injecting, intravenous, and so on. Counseling given to students of SMP N 4 Siak Hulu. Teens are a real target. Regarding new things, including the influence of cigarettes and drugs, teenagers at SMP 4 Siak Upstream are given counseling about smoking and drugs, so they can understand the dangers and consequences that can be caused by smoking and drugs At the time of the extension process students were quite active and enthusiastic in following the counseling process that was given. Then the pre-test and post-test were carried out, at the time of the pre-test there were still many questions that the students had not been able to answer, but at the time of the post-test they were able to answer the previous questions. So that students receive and understand the information provided properly.
\end{abstract}

\section{Keywords: Cigarettes, Drugs, Students of SMP N 4 Siak Hulu}

\begin{abstract}
ABSTRAK
Rokok merupakan zat adiktif yang bila digunakan dapat mengakibatkan bahaya kesehatan bagi individu dan masyarakat. Narkoba merupakan zat kimia yang dapat mengubah keadaan psikologi seperti perasaan, pikiran, suasana hati serta perilaku jika masuk ke dalam tubuh manusia baik dengan cara dimakan, diminum, dihirup, suntik, intravena, dan lain sebagainya. Penyuluhan diberikan kepada siswa SMP N 4 Siak Hulu. Remaja merupakan sasaran yang rentan terpengaruh terhadap hal-hal baru, termasuk pengaruh rokok dan narkoba, maka dari itu remaja di SMP 4 Siak hulu diberikan penyuluhan mengenai rokok dan narkoba, sehingga mereka dapat memahami bahaya serta akibat yang dapat ditimbulkan dengan mengkonsumsi rok dan narkoba. Pada saat proses penyuluhan siswa cukup aktif dan bersemangat mengikuti proses penyuluhan yang diberikan. Kemudian dilakukan pre test dan post tes, pada saat pre test masih banyak pertanyaan yang belum bisa terjawab oleh siswa, namun pada saat post test mereka mampu menjawab pertanyaan sebelumnya. Sehingga disimpulkan bahwa siswa menerima dan memahami informasi yang diberikan dengan baik.
\end{abstract}

\section{Kata Kunci: Rokok, Narkoba, Siswa SMP N 4 Siak Hulu}




\section{PENDAHULUAN}

Rokok adalah silinder dari kertas berukuran panjang antara 70-120 mm dengan diameter $10 \mathrm{~mm}$ yang berisi daundaun tembakau yang telah di cacah. Rokok dibakar disalah satu ujungnya dan dibiarkan membara agar asapnya dihirup melalui mulut pada ujung lain. Bahan dasar rokok adalah tembakau. Tembakau terdiri dari berbagai bahan kimia yang dapat membuat seseorang ketagihan, walaupun mereka tidak ingin mencobanya lagi.

Sangat ironis memang bahwa manusia sangat memperhatikan keseimbangan alam akibat proses pembakaran bahan bakar oleh industri yang mengeluarkan polusi tetapi dilain pihak orang-orang dengan sengaja mengalirkan gas produksi pembakaran rokok ke paru-paru mereka. Terutama remaja masa kini, masa remaja merupakan masa dimana seorang individu mengalami peralihan dari satu tahap ke tahap berikutnya dan mengalami perubahan baik emosi, tubuh, minat pola perilaku, dan juga panuh dengan masalah-masalah.

Narkoba merupakan singkatan dari Narkotika, Psikotropika dan Bahan Adiktif lainnya. Terminologi narkoba familiar digunakan oleh aparat penegak hukum seperti polisi (termasuk didalamnya Badan Narkotika Nasional), jaksa, hakim dan petugas Pemasyarakatan. Selain narkoba, sebutan lain yang menunjuk pada ketiga zat tersebut adalah Napza yaitu Narkotika, Psikotropika dan Zat Adiktif. Istilah napza biasanya lebih banyak dipakai oleh para praktisi kesehatan dan rehabilitasi. Akan tetapi pada intinya pemaknaan dari kedua istilah tersebut tetap merujuk pada tiga jenis zat yang sama.

Menurut UU No.22 Tahun 1997 tentang Narkotika disebutkan pengertian Narkotika adalah "zat atau obat yang berasal dari tanaman atau bukan tanaman baik sintetis maupun semi sintetis yang dapat menyebabkan penurunan atau perubahan kesadaran, hilangnya rasa, mengurangi sampai menghilangkan rasa nyeri, dan dapat menimbulkan ketergantungan".

\section{METODE KEGIATAN}

Metode pengabdian masyarakat ini dilaksanakan dalam bentuk penyuluhan dengan mengangkat tema " Penyuluhan Rokok dan Narkoba di SMP N 4 Siak Hulu " dengan memberikan ceramah langsung dan leafleat berisi materi dan gambar yang menarik serta Tanya jawab seputar bahaya dan akibat dari rokok dan narkoba. Kemudian melakukan pre test dan post test seputar materi penyuluhan, serta memberikan doorprice bagi siswa yang mampu menjawab pertanyaan yang diberikan. 


\section{HASIL DAN PEMBAHASAN}

Hasil

Dari kegiatan penyuluhan yang dilakukan kepada anak-anak SMPN 4 Siak Hulu berjalan dengan lancar. Kegiatan ini dilakukan pada hari Rabu tanggal 19 Desember 2018 pada pukul 07:00 wib s/d selesai dengan peserta anak-anak SMP. Sebelum melakukan penyuluhan yang kelompok lakukan adalah dengan memberikan pretest untuk melihat bagaimana tingkat pengetahuan anak-anak SMP tersebut mengenai rokok dan narkoba. Hanya beberapa dari anak SMP yang mampu menjawab pretest tersebut,tapi setelah dilakukan penyuluhan atau pemberian informasi mengenai rokok dan narkoba maka semua anak SMP bisa menjawab.

Untuk penyuluhan yang kelompok lakukan adalah memberikan materi dan penjelasan tentang rokok dan narkoba. Anak-anak SMP diberitau tentang bahaya rokok dan narkoba tersebut yang mana sebelum diberikan penyuluhan atau pengetahuan mereka belum mengetahui bahaya dari kedua tersebut. Tetapi setelah diberi penyuluhan anak-anak SMP sudah mengetahui bahaya dari rokok dan narkoba.

\section{Pembahasan}

Dari kegiatan penyuluhan yang dilakukan pada anak SMPN 4 SIAK
HULU, awalnya dari kami melakukan bina suasana agar anak-anak menjadi semangat, kemudian kami memberikan materi tentang rokok dan narkoba. Rokok berbahaya karena setiap rokok mengandung lebih dari 4000 jenis bahan kimia,dimana 400 dari bahan-bahan tersebut dapat menyebabkan kanker, rokok mengandung zat-zat berbahaya didalamnya antara lain: nikotin yang menyebabkan ketergantungan , meningkatkan adrenalin yang membuatnya berdebar lebih cepat dan bekerja lebih keras, karbonmonoksida yang dapat merusak lapisan pembulu darah dan dapat menaikan kadar lemak pada dinding pembulu darah yang dapat menyebabkan penyumbatan serta dapat menyebabkan tumbuhnya sel kanker.

Tar terbagi atas : DDT adalah pestisida untuk membunuh nyamuk dan semut,arsenik adalah racun pembunuh semut putih dan banyak digunakan pembunuh terkenal, hydrogen cyanida adalah racun digunakan untuk hukuman mati pada kamar gas, vinyl chlorid zat kimia yang digunakan untuk membunuh plastik,kolonium-210 adalah radioaktif, naphthhlene zat mematikan terdapat juga pada kapur barus, cadmium yang terdapat pada batray, formaldeleyde bahan kimia yang biasanya dikenal untuk membalsam mayat. Ada pun beberapa alasan untuk berhenti merokok : penyakit jantung dan 
stroke,kanker

paru,kanker

mulut,osteoporosis,gangguan

mata,gangguan aliran darah. Penyakit bulger yang dapat menyebabkan amputasi jari tangan atau kaki antara lain adalah: impotensi, gigi berbercak dan nafas bau, anda dan disekitar menjadi bau, panutan yang buruk bagi anak dan habiskan biaya.

Adapun materi narkoba adalah narkoba singkatan dari narkotika dan obatobatan terlarang yang sering disalah gunakan. Dimana penyalah gunaan obat adalah pemakaian diluar indikasi medik,tanpa petunjuk atau tanpa resep dokter, pemakaian sendiri secara relatif teratur sekurang kurangnnya selama satu bulan. Obat atau zat yang sering disalahgunakan adalah obat alcohol, benzodiazepine, mariuana, amfetamin, kokain, opium, heroin, morfin, dan lainlain. Semua jenis obat tersebut dapat mengakibatkan gangguan mental yang disebabkan oleh efek langsung dari zat tersebut terhadap susunan saraf pusat.

Adapaun ciri-ciri orang yang ketergantungan obat yaitu : keinginan yang tak tertahankan terhadap zat yang dimaksud; kecenderungan untuk menambah takaran sesuai dengan takaran tubuh, ketergantungan psikis apabila pemakaian zat diberhentikan akan menimbulkan kegelisahan, depresi dan kecemasan; ketergantungan fisik sesuai dengan jenis obat; dan gerakan tak terkontrol. Komplikasi dari penyalahgunaan zat yaitu selain gangguan otak, dapat menyebabkan gangguan hati, usus, sek, kelainan bayi (bila hamil) dan resiko terkena kanker.

Cara mencegah obat-obat berhaya yaitu narkoba adalah : ketahuilah bahwa obat tersebut sangat berbahaya dan jangan sekali-kali mencoba, bina hubungan yang harmonis dengan orang tua sehingga perilaku kita lebih terkontrol, katakan tidak bila ada yang menawari, dan konsultasi kepada petugas kesehatan bila memiliki masalah kesehatan termasuk gangguan pikiran. Cara pengobatan dan penyembuhan dari obat-obat berbahaya yaitu narkoba adalah pengobatan pasien yang mengalami ketergantungan obat tergantung dari tingkat keparahan/berat/ringan tingkat ketergantungan. Sedangkan penyembuhannya yaitu dengan memerlukan waktu yang relative lama dan membutuhkan biaya yang besar.

\section{Kesimpulan}

Rokok berbahaya karena setiap rokok mengandung lebih dari 4000 jenis bahan kimia,dimana 400 dari bahan-bahan tersebut dapat menyebabkan kanker. Rokok mengandung zat-zat berbahaya didalamnya antara lain: nikotin yang menyebabkan ketergantungan, meningkatkan adrenalin yang membuatnya 
berdebar lebih cepat dan bekerja lebih keras; karbonmonoksida yang dapat merusak lapisan pembulu darah dan dapat menaikan kadar lemak pada dinding pembulu darah yang dapat menyebabkan penyumbatan; tar yang dapat tumbuuhnya sel kanker.

Narkoba adalah obat atau zat yang sering disalahgunakan adalah obat alcohol, benzodiazepine, mariuana, amfetamin, kokain, opium, heroin, morfin, dan lainlain. Semua jenis obat tersebut dapat mengakibatkan gangguan mental yang disebabkan oleh efek langsung dari zat tersebut terhadap susunan saraf pusat.

Penyuluhan rokok dan narkoba banyak memberikan manfaat bagi siswasiswi SMPN 4 Siak Hulu bentuk nyatanya adalah adanya peningkatan pengetahuan. Setelah terjadi peningkatan pengetahuan diharapkan tumbuhnya kesadaran anak
SMP akan bahaya apabila menggunakan rokok dan narkoba dalam kesehatan diri dan dapat mengaplikasikan ilmu yang diterima dalam kehidupan sehari-hari.

\section{DAFTAR PUSAKA}

Aditama, T. "Masalah Merokok dan Penanggulangannya." Mirasantika, Juli 20CC07, hlm. 13 Alatas, H. 2006. Bahaya Merokok. Jakarta: Fakultas Kedokteran Universitas Indonesia.www.antirokok.or.id/upayapencegahan-dari merokok/www.id.wikipedia.org/penge rtian-rokok/http://www.bnn.go.id http://www.negarahukum.com/hukum/pen gertian-narkotika.html http://edukasi.net/index.php?mod=scrip\&c $\mathrm{md}=$ bahan\%20Belajar/Materi\%20pok $\mathrm{ok} / \mathrm{view} \& \mathrm{id}=350 \mathrm{uniq}=3455$ 